
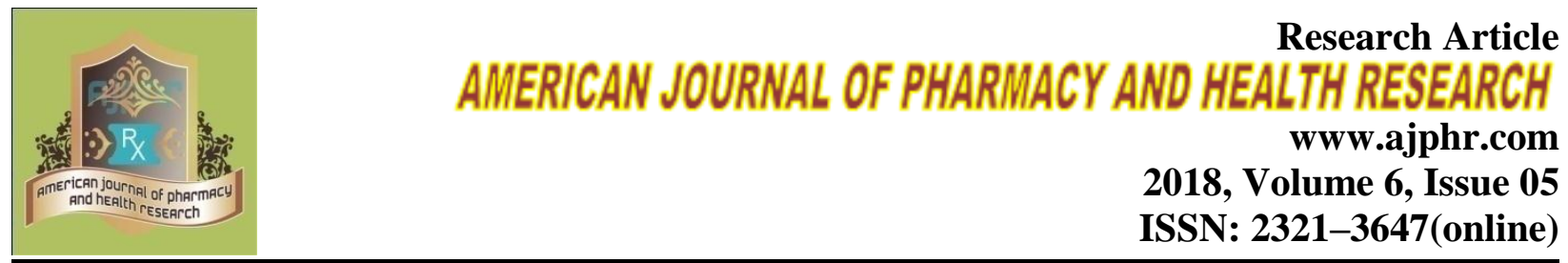

\title{
Study of Prescribing Pattern In Treatment of Pediatric Pneumonia and Parent Counselling In Tertiary Care Teaching Hospital
}

\author{
Gade Ashok Reddy ${ }^{1 *}$, K.Saravanan ${ }^{1}$, S.Chidambaranathan ${ }^{2}$ \\ 1.Department of Pharmacy, Annamalai University \\ 2., Rajah Muthiah Medical College \& Hospital, Annamalai University
}

ABSTRACT

Pneumonia is a lower respiratory tract infection that specially affects the lungs and is caused by micro-organisms. Pneumonia kills more children than any other illness, more than AIDS, malaria and measles combined. It occurs in people of all ages, although the clinical manifestations are most severe in the very young, the elderly, and the chronically ill. The aim of study was to assess the prescribing pattern of drugs used in treatment of pneumonia in children and to provide parent counselling regarding post discharge drug administration in a tertiary care teaching hospital. A Prospective Observational Study which was carried out in the Department of Paediatrics of Rajah Muthiah Medical College Hospital in Chidambaram, Cuddalore District, Tamil nadu in the period of June 2016 to October 2016 (5 months). The patient demographics, antibiotics prescribed, discharge advices were collected in a specially designed data collection form. A total of 30 patients were enrolled post obtaining consent from parents into the study. 19 patients $(63.33 \%)$ were male and 11 patients $(36.66 \%)$ were female. The age distribution of the study showed majority of patients with pneumonia aged between 2months and 1 year, for $53.33 \%$ of the total whereas the patients at 4-12 year occupied the least. Drug use pattern showed all the 30 patients were prescribed with various nebulizing agents. In which 25 patients were mostly prescribed with $3 \%$ NACL + O2. Among 30 patients, 7 patients underwent mono therapy, 16 patients underwent dual therapy, 3 patients underwent triple therapy \& 4 patients were not treated with antibiotics. Counselling for patient caretakers upon discharge were based upon certain parameters which included dose, dosing interval, side effects. Study outcomes concluded that male patients and patients with age group > 2 months and <1year were affected mostly with pneumonia. The study suggests that occurrence and recovery of young patients from pneumonia can be greatly improved if the parent/care taker is aware of causes of the disease and appropriate treatments Cephalosporins are the most used antibiotics among the patients and is of first choice.

Keywords: Pediatrics, Pneumonia, Antibiotics.

*Corresponding Author Email: ashokreddy809@gmail.com

Received 24 April 2018, Accepted 30 April 2018

Please cite this article as: Reddy GA et al., Study of Prescribing Pattern In Treatment of Pediatric Pneumonia and Parent Counselling In Tertiary Care Teaching Hospital. American Journal of Pharmacy \& Health Research 2018. 


\section{INTRODUCTION}

Pneumonia is an inflammation of parenchyma of the lungs. It is a lower respiratory tract infection that specially affects the lungs and is caused by micro-organisms. Pneumonia kills more children than any other illness, more than aids, malaria and measles combined. Approximately over 2 million children under the age of five in developing countries die each year from pneumonia. Over 1090 Indian children under five years of age die every day. Prompt treatment of pneumonia is usually with a full course of appropriate antibiotics. According to WHO reports that over 1 in 5 parent/caregivers only know about Pneumonia . In pneumonia not only antibiotics are prescribed but also different other drugs are given, therefore pharmacists should be able to evaluate the management of such kind of drug therapy. Viral pneumonia caused by RSV (respiratory syncytial virus) influenza, Para-influenza or adenovirus and accounts for $40 \%$ of the cases, In over two third of the cases, common-bacteria cause Pneumonia like Kelbsiella, E-coli, Gram-positive organisms like Pneumococci, Staphylococci, Atypical organisms like Chlamydia and mycoplasma can also cause pneumonia. Risk factors associated with pneumonia are low birth weight, malnutrition, vitamin A deficiency, lack of breastfeeding, passive smoking, poor socio-economic status, large family size, family history of bronchitis, overcrowding, indoor and outdoor air pollution. Signs and Symptoms of pneumonia are fever, chills, cough, unusually rapid breathing, breathing with grunting or wheezing sounds, vomiting, chest pain and abdominal pain. Diagnosis of pneumonia can be done by complete blood count, cultures, imaging studies and cold agglutinin test. Children with pneumonia should be treated with proper antibiotics like Penicillins, Broad spectrum Cephalosporins, Macrolides and Amino glycoside for specific time of period in hospital and later at home.

\section{Aims and Objectives:}

The main aim was to study the prescribing pattern of drugs used in treatment of pneumonia in children and to provide parent counselling regarding post-discharge drug administration in a tertiary care teaching hospital. To study the prescribing pattern of drugs used in treatment of pneumonia in children in paediatrics ward (In patients). To assesses the impact of parent counselling regarding post discharge drug administration.

\section{MATERIALS AND METHOD}

Study was a prospective observational study conducted in Department of Paediatrics, Rajah Muthiah Medical College Hospital, Annamalai University, Annamalai Nagar, Tamil Nadu, which is a 1400 bedded multi-speciality tertiary care teaching hospital located in rural South India during 
the months of June 2016 to October 2016. Patients included in the study were selected based on Inclusion and exclusion criteria. In-Patients admitted to Paediatrics ward aged below 12 years, who were diagnosed for pneumonia were included in the study. Parent consent was obtained for the children to be included into the study. Non-cooperative patients and patients from who follow up cannot be done were excluded.

\section{RESULTS AND DISCUSSION}

A total of 30 patients were enrolled in this study, of these 19 patients $(63.33 \%)$ were male and 11 patients $(36.66 \%)$ were female.

Table 1: Patient Distribution

\begin{tabular}{llll}
\hline S.no & Gender & No.of patients & \% of patients \\
\hline 1. & Male & 19 & 63.33 \\
2. & Female & 11 & 36.66 \\
\hline
\end{tabular}

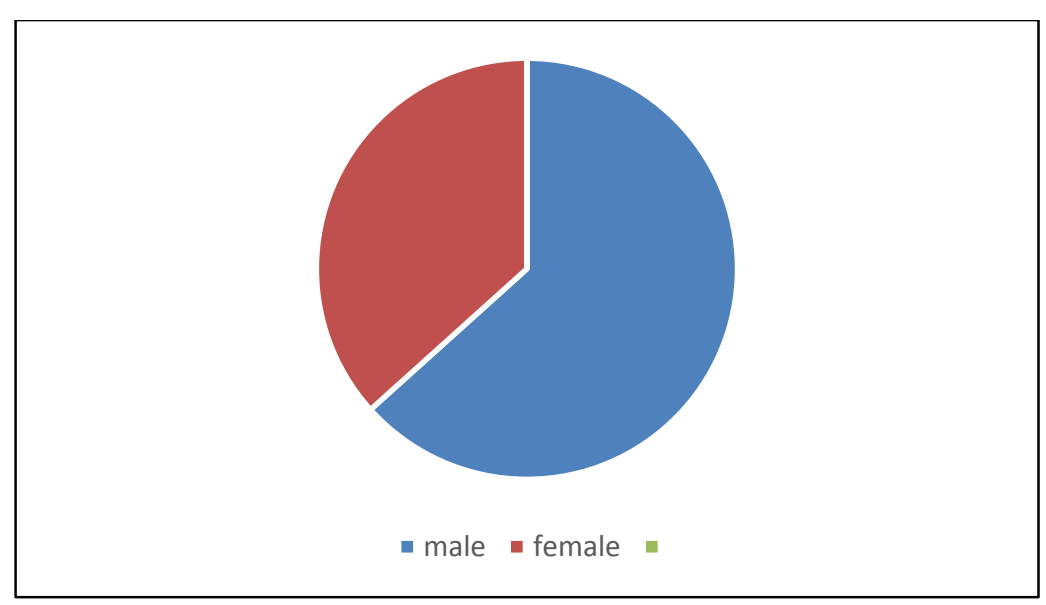

The age of the patients were in the range as follows showed majority of patients with pneumonia belongs to 2 months -1 years, accounting for $53.33 \%$ followed by $4-6$ years accounting $6.66 \%$ occupies the least.

Table: 2 Age Wise Distribution

\begin{tabular}{llll}
\hline S.No & Age & Number of Patients & \% of Patients \\
\hline 1. & 2 Months- 1 Years & 16 & 53.33 \\
2. & 1-2 Years & 08 & 26.66 \\
3. & 2-4Years & 04 & 13.33 \\
4. & 4-6 Years & 02 & 06.66 \\
\hline
\end{tabular}




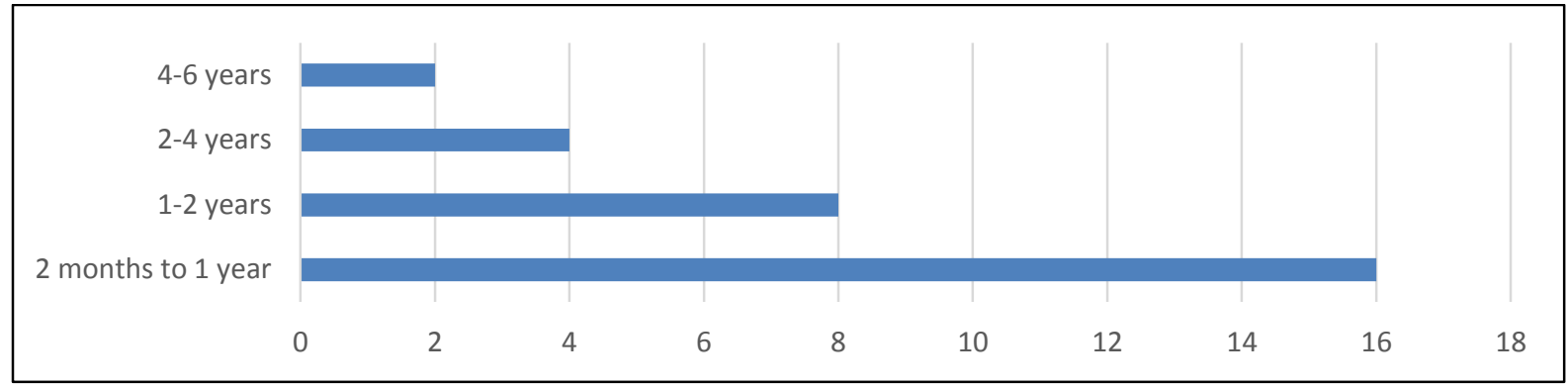

All the patients were prescribed with various antibiotics. In which 24 patients were prescribed with Cephalosporins, 6 patients were prescribed with penicillin derivative and few patients were given a combination of one or more antibiotics

Table : 3 Antibiotic Distribution

\begin{tabular}{lll}
\hline S.No & Antibiotics & Total No Of Patients \\
\hline 1. & Cephalosporins & 24 \\
2. & Penicillin derivatives & 06 \\
3. & Aminoglycosides & 20 \\
4. & Macrolides & 02 \\
\hline
\end{tabular}

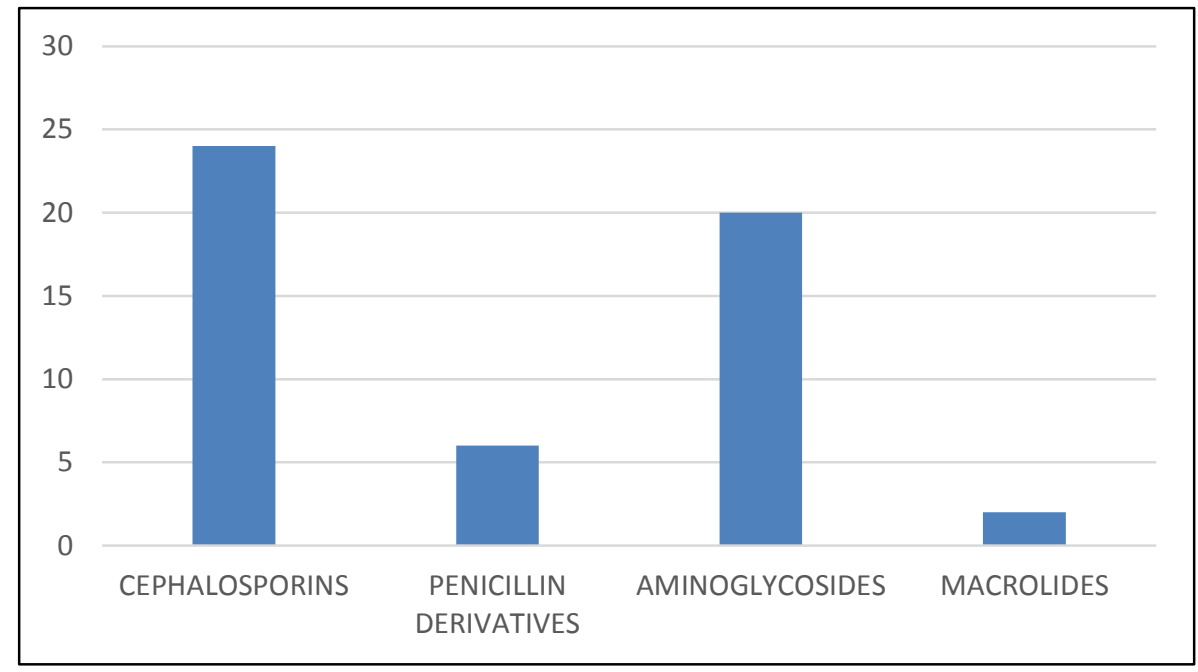

Among 30 patients, 7 patients underwent mono therapy, 16 patients underwent dual therapy, 3 patients underwent triple therapy and 4 patients were not treated with antibiotics.

Table: 4 Antibiotic Regimens

\begin{tabular}{lll}
\hline S.no & Antibiotics & Total no of patients \\
\hline 1. & Single therapy & 07 \\
2. & Dual therapy & 16 \\
3. & Triple therapy & 3 \\
4. & No antibiotics & 4 \\
\hline
\end{tabular}




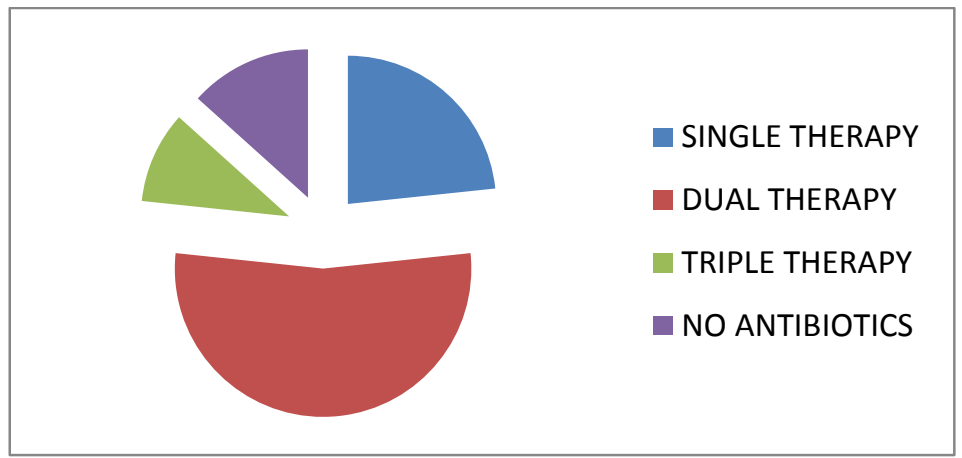

Total 30 patients among them 24 patients were prescribed various antibiotics in that cefotaxime 11 patients followed by ceftriaxone 13 patients.

Table: 5 Distribution of Cephalosporins

\begin{tabular}{lll}
\hline S.no & Drugs & No of Patients \\
\hline 1. & Cefotaxime & 11 \\
2. & Ceftriaxone & 13 \\
\hline
\end{tabular}

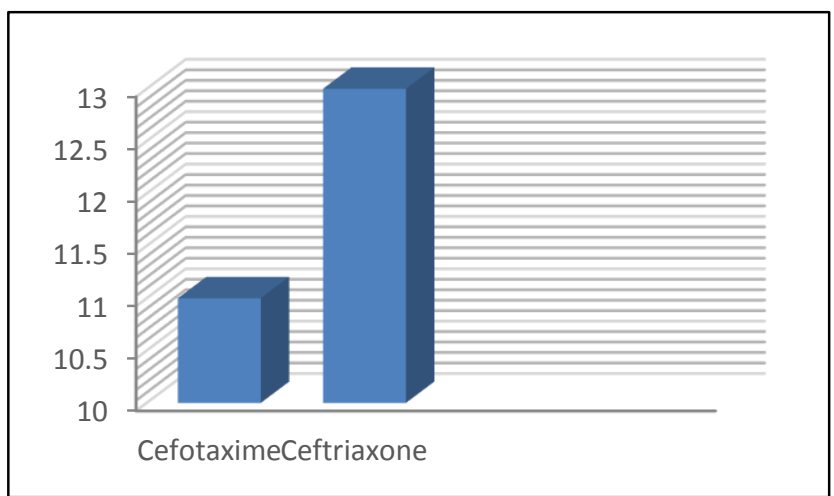

In this study 6 patients were prescribed with penicillin derivatives and among them Ampiclox (03 patients) were commonly prescribed.

Table: 6 Penicillin Derivatives Prescribed

\begin{tabular}{lll}
\hline S.no & Drugs & No of patients \\
\hline 1. & Ampicillin & 02 \\
2. & Amoxicillin & 01 \\
3. & Ampiclox & 03 \\
\hline
\end{tabular}


In this study 20 patients were prescribed with aminoglycosides category of amikacin antibiotics are prescribed.

Table: 7 Distribution Of Aminoglycoside Antibiotics

\begin{tabular}{lll}
\hline S.no & Drugs & No of patients \\
1. & Amikacin & 20 \\
\hline
\end{tabular}

In this study 02 patients were prescribed with Macrolide category of azithromycin were prescribed.

\section{Table: 8 Distribution Of Macrolide Antibiotics}

\begin{tabular}{lll}
\hline S.no & Drugs & No of patients \\
1. & Azithromycin & 02 \\
\hline
\end{tabular}

All the 30 patients were prescribed with various nebulizing agents. In which 25 patients were mostly prescribed with $3 \% \mathrm{Nacl}+\mathrm{O} 2$.

Table 9 Distribution of Nebulizing Agents

\begin{tabular}{lll}
\hline S.no & Drugs & No of patients \\
\hline 1. & 3\% Nacl + O2 & 25 \\
2. & Levosalbutamol $+2 \%$ Nacl & 13 \\
3. & Budesonide & 02 \\
4. & Duolin (Salbutamol, Ipratropium bromide) & 03 \\
\hline
\end{tabular}

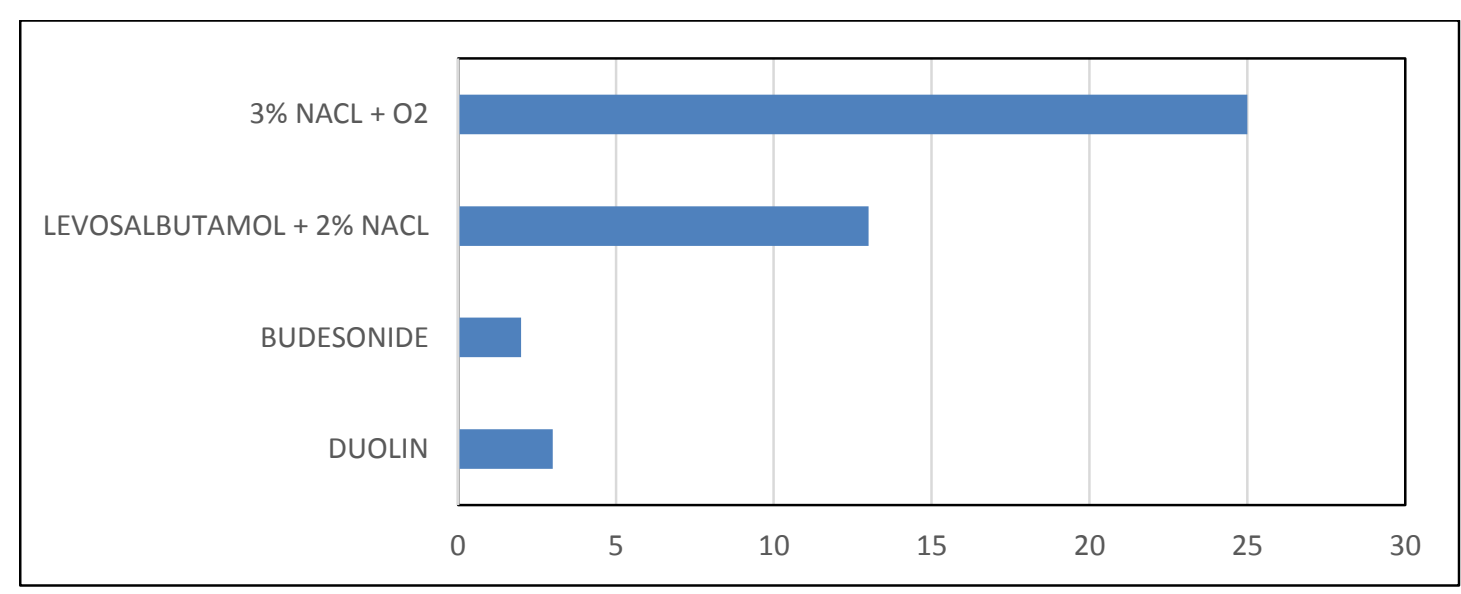

All the 30 patients were prescribed with various medications on discharge. In which 14 patients were mostly prescribed with antibiotics, 14 patients were prescribed with anti-pyretics, 17 patients with mucolytics, and 09 patients with bronchodilators and 10 with vitamin supplements.

Table: 10 Post-Discharge Medications:-

\begin{tabular}{lll}
\hline S.no & Drugs & No of patients \\
\hline 1. & Antibiotics & 14 \\
2. & Anti-pyretics & 14 \\
3. & Mucolytics & 17 \\
4. & Bronchodilators & 09 \\
5. & Vitamins & 10 \\
\hline
\end{tabular}




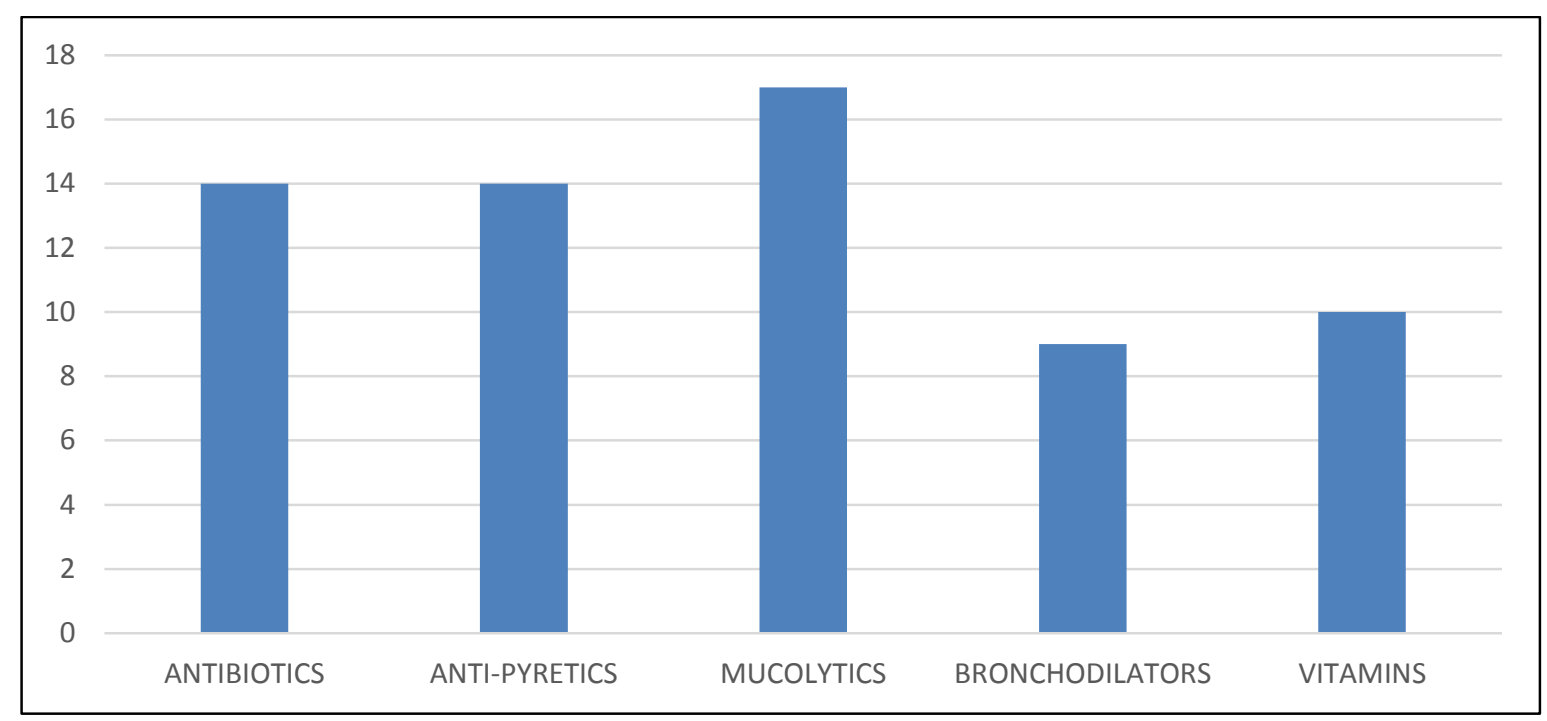

The patients who have responded well towards the therapy had short hospital stay and were prescribed with few broad spectrum cephalosporins for a short period of time

Table: 11 Antibiotics In Discharge Medications

\begin{tabular}{lll}
\hline S.no & Antibiotics & No of patients \\
\hline 1. & Ampicillin + Cloxacillin & 1 \\
2. & Cefixime & 10 \\
3. & Azithromycin & 03 \\
\hline
\end{tabular}

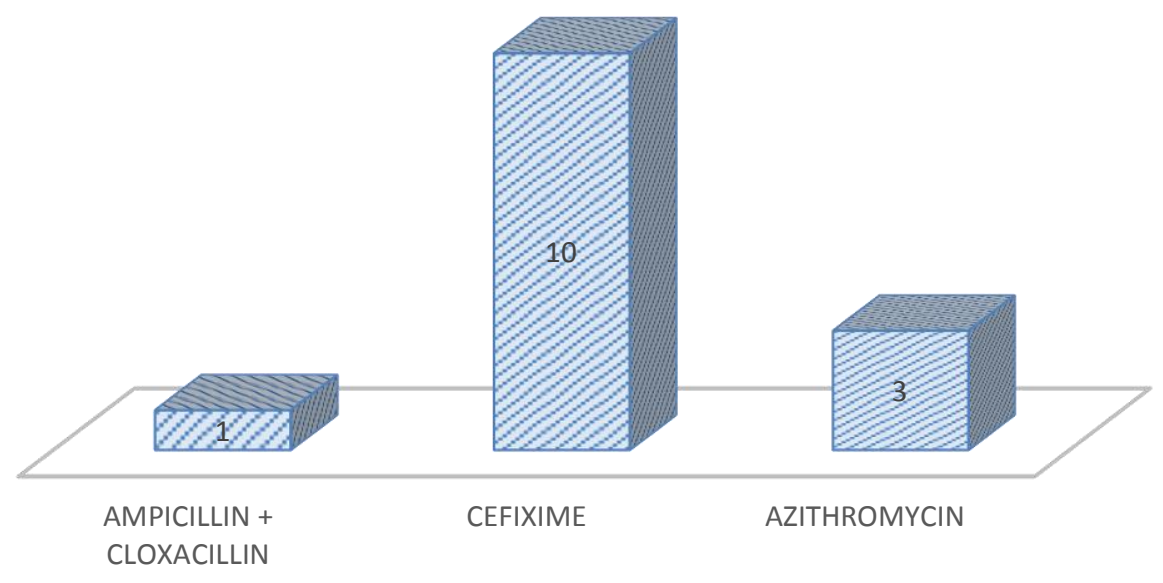

Counselling of patients on discharge was based upon certain parameters listed below, to know the efficiency of counselling towards the parent or caretaker with certain queries. Queries were, whether the parent was well aware about dose (yes from 08 parents, no from 22 patients). The second query was whether the patient was well aware about administration (yes from 20 parents, no from 10 patients), the third query was whether the parent was well aware about side effects (yes from 08 parents, no from 22 patients), and the fourth query was whether the parent understood the dosing interval (yes from 19 parents, no from 11 patients). 
Table: 12 Evaluation The Knowledge Of Parent Regarding Post-Discharge Medications

\begin{tabular}{llll}
\hline Parameters & yes & no & no of patients \\
\hline Well aware about dose & 8 & 22 & 30 \\
Well aware about administration & 20 & 10 & 30 \\
Well aware about side effects & 08 & 22 & 30 \\
Dosing interval & 19 & 11 & 30 \\
\hline
\end{tabular}

\section{DISCUSSION:}

This study describes the prescribing pattern of drugs used in treatment of pneumonia in children admitted in tertiary care teaching hospital and providing parent counselling regarding post discharge drug administration in 30 patients below 2 months to 12 years. The aim of the study is to observe the prescribing pattern of drugs used in treatment of pneumonia and providing parent counselling regarding post discharge drug administration. A total of 30 patients were enrolled in this study, of these $19(63.33 \%)$ were male and $11(36.66 \%)$ were female. The age distribution of the study showed majority of patients with pneumonia belonged to 2 months -1 years, for $53.33 \%$ of the total whereas the patients at 4-12 year occupies the least. All the 30 patients were prescribed with various nebulizing agents. In which 25 patients were mostly prescribed with $3 \%$ NACL + O2. Among 30 patients, 7 patients underwent mono therapy, 16 patients underwent dual therapy, 3 patients underwent triple therapy, \& 4 patients are not treated with antibiotics. All the 30 patients were prescribed with various antibiotics. Among 30 patients, 24 patients were prescribed with cephalosporins. Ceftriaxone (13 patients) was the commonly prescribed cephalosporin. In this study 6 patients were prescribed with penicillin derivatives and among them Ampiclox (03) was the most commonly prescribed. In this study 20 patients were prescribed with aminoglycoside antibiotics. In this study 02 patients were prescribed with Macrolides and among them Gentamycin was prescribed. All the 30 patients were prescribed with various medications on discharge in which 14 patients were prescribed with antibiotics, 14 patients were prescribed with anti-pyretics, 17 patients with mucolytics, 09 patients with bronchodilators and 10 patients with vitamin supplements. Discharge counselling was based on certain parameters; to know the efficiency of counselling towards the parent or caretaker certain queries were done. Queries were based on whether the parent was well aware about dose (yes from 08 parents, no from 22 patients). The second query was whether the patient was well aware about administration (yes from 20 parents, no from 10 patients), the third query was whether the parent was well aware about side effects (yes from 08 parents, no from 22 patients), and the fourth query was whether the parent understood the dosing interval (yes from 19 parents, no from 11 patients). 


\section{CONCLUSION:}

My study shows that patients with age group > 2 months-1year were mostly affected with pneumonia. All patients were prescribed with various antibiotics. Among which, 7 patients underwent mono therapy, 16 patients underwent dual therapy, 3 patients underwent triple therapy \& 4 patients were not treated with antibiotics. 24 patients were prescribed with cephalosporins. Ceftriaxone (13 patients) was the common prescribed cephalosporin, 6 patients were prescribed with penicillin derivatives and among them ampiclox (03) was the prescribed drug; 20 patients were prescribed with aminoglycosides; and 02 patients were prescribed with macrolides. All the 30 patients were prescribed with nebulizing agents, 25 patients were prescribed with 3\% NACL+O2 (25); Levosalbutamol + 2\% Nacl (13); Budesonide (02); Duolin (03). All 30 patients were prescribed with various drugs post-discharge. In which 14 patients were prescribed with antibiotics, 14 patients were prescribed with anti-pyretics, 17 patients with mucolytics, and 09 patients with bronchodilators and 10 with vitamin supplements. Discharge counselling was done based on certain parameters and to know the efficiency of counselling towards the parent or caretaker certain queries were done upon topics like parent awareness about dose (yes from 08 parents, no from 22 patients), drug administration (yes from 20 parents, no from 10 patients), side effects (yes from 08 parents, no from 22 patients), dosing interval (yes from 19 parents, no from 11 patients). The study suggests that occurrence and recovery of young patients from pneumonia can be greatly improved if the parent/care taker is aware of causes of the disease and appropriate treatments

\section{LIMITATION OF THE STUDY:}

The number of participants obtained and the study duration were limited, if the study was conducted for a longer duration, more significant results may have been obtained.The study was limited to Department of Paediatrics in RMMCH; if the study was extended to other hospitals in Chidambaram it would have significantly improved the results.

\section{REFERENCES:}

1. Hall CB. Respiratory syncytial virus and Para influenza virus. N Engl J Med 2001;344:1917-1928.

2. King VJ, Viswanathan M, Bordley WC, et al. Pharmacologic treatment of bronchiolitis in infants and children: A systematic review. Arch PediatrAdolesc Med 2004;158:127-137.

3. Mason CM, Nelson S. Pulmonary host defenses and factors predisposing to lung infection. Clin Chest Med 2005;26:11-17. 
4. Yip TTC, Chan JW, Cho WCS, et al. Protein chip array profiling analysis in patients with severe acute respiratory syndrome identified serum amyloid a protein as a biomarker potentially useful in monitoring the extent of pneumonia. ClinChem 2005;51:47-55.

5. Porzecanski I, Bowton DL. Diagnosis and treatment of ventilator associated pneumonia. Chest 2006:130:597-604.

6. Hall CB. Respiratory syncytial virus and para-influenza virus. N Engl J Med 2001;344:1917-1928.

7. King VJ, Viswanathan M, Bordley WC, et al. Pharmacologic treatment of bronchiolitis in infants and children: A systematic review. Arch Pediatr Adolesc Med 2004;158:127-137.

8. File Jr. TM, Garau J, Blasi F, et al. Guidelines for empiric antimicrobial prescribing in community-acquired pneumonia. Chest 2004;125:1888- 1901.

9. Reimer LG. Community-acquired bacterial pneumonias. Semin Respir Infect 2000;15:95100.

10. Shefet D, Robenshtok E, Paul M, et al. Empirical atypical coverage for inpatients with community-acquired pneumonia: Systematic review of randomized controlled trials. Arch Intern Med 2005;165:1992-2000.

11. Lynch III JP. Hospital-acquired pneumonia: Risk factors, microbiology, and treatment. Chest 2001;119:373S-384S.

12. Levison ME. Anaerobic pleuro-pulmonary infection. CurrOpin Infect Dis 2001;14:187191.

13. Lim WS, Macfarlane JT. Hospital acquired pneumonia. Clin Med 2001;1:180-184.

14. Fiel S. Guidelines and critical pathways for severe hospital-acquired pneumonia. Chest 2001;119:412S-418S.

15. Plouffe JF. Importance of typical pathogens of community acquired pneumonia. Clin Infect Dis 2000;31(Suppl 2):S35-S39.

16. Hammerschlag MR. Mycoplasma pneumoniae infections. CurrOpin Infect Dis 2001;14:181-186.

17. Viscoli C, Varnier O, Machetti M. Infections in patients with febrile neutropenia: Epidemiology, microbiology, and risk stratification. Clin Infect Dis 2005;40:S240-S245.

\section{AJPHR is}

Peer-reviewed

monthly

Rapid publication

Submit your next manuscript at

editor@ajphr.com / editor.ajphr@gmail.com 